\title{
Iparker: A Smart Car Parking System for Smart City
}

\author{
Jirapure Piyush \\ D. Y. Patil College Of \\ Engineering, \\ Ambi, Pune
}

\author{
Lambrud Sachin \\ D. Y. Patil College Of \\ Engineering, \\ Ambi, Pune
}

\author{
Sanap satish \\ D. Y. Patil College Of \\ Engineering, \\ Ambi, Pune
}

\author{
Sargar Samadhan \\ D. Y. Patil College Of \\ Engineering, \\ Ambi, Pune
}

\begin{abstract}
As the world's population keeps increasing and the attention of cars in cities rises, our civilians face the significant challenge of global congestion. Parking plays a most important role in the key to this problem, given that around $30 \%-35 \%$ of the cars driving on a city's paths at any given instant are looking for a parking space. The proposed system solves the current parking problems by proposing certain parking reservations with the lowest possible cost and searching time for drivers and the highest income and resource utilization for parking supervisors.

In this work QR-Code applied to store and update the reservations status. The new system is based on mathematical modelling using mixed-integer linear programming (MILP) with the objective of reducing the total financial cost for the drivers and exploiting the utilization of parking resources. The system present a new smart car parking system, named iParker, with static resource planning, dynamic resource allocation and pricing models, to optimize the parking system for both parking managers and drivers. The assistances of the work include: a) increasing parking resource utilization, b) increasing parking revenue, b) improving parking experience of drivers by lowering cost, parking spot searching and walking times. The new concept is to combine real time reservations with share time reservations, thus a driver can reserve a spot while heading to it e.g., few minutes away and also can reserve it at any time earlier e.g., many days away
\end{abstract}

\section{General Terms}

Searchable encryption, multi-keyword ranked search, dynamic update, cloud computing.

\section{Keywords}

Data centre, Central request centre (CRC), Qr code reader, Mixed integer linear programming (MILP),Possions distribution, exponential distribution, Smart car parking.

\section{INTRODUCTION}

Parking is an expensive process in terms of either money or the time and effort spent for the "free spot chasing." Current studies reveal that a car is parked for 95 present of its lifetime and only on the road for the other 5 present. If we take England in 2014 as an example, on average a car was driven for 361 hours a year according to the British National Travel Survey yielding about 8404 hours in which a car would be parked. Now where would you park your car for these very long hours? Cruising for parking is naturally the first problem caused by the increase of car owners globally. [2]On average, 30 present of traffic is caused by drivers wandering around for parking spaces. In 2006, a study in France revealed an estimation that 70 million hours were spent every year in France only in searching for parking which resulted in the loss of 700 million euros annually.[3]In 2011, a global parking survey by IBM states that 20 minutes is spent on average in searching for a coveted spot. With these statistics, we can assume that a great portion of global pollution and fuel waste is related to cruising for parking. Parking spaces are found to be more than plenty in some places and very rare to find in others. Pricing policies had played an important role in the overall parking availability for decades. Here comes the important question: do we need to have more parking spaces or do we need better parking management? We believe it is the later and thus the motivation behind this work is about better parking management with fair and profitable pricing policies.[6] The work presented in this paper combines parking reservation and pricing models to overcome the parking problems.

\section{PROBLEM STATEMENT}

Parking facilities in major cities has become a huge problem. There is lack of proper free spaces for parking and there has been increase in the number of vehicles, but without sufficient parking spaces. Such growing number of small vehicles especially cars and micro buses have created mess in the city including the increase in traffic jam. In general when any driver looking for parking, this will lead to losing a precious time and also fuel. Every person searches for parking nearly 5 minute this will lead consumption of nearly 10 rupees of fuel which is 500 rupees in month and yearly nearly 6000 rupees.

The problem is addressed in proposed system which will solves the current parking problems by offering guaranteed parking reservations with the lowest possible cost and searching time for drivers and the highest income and resource utilization for parking managers. Smart parking system that is based on intelligent resource allocation, reservation, and pricing

\section{PROPOSED SYSTEM}

iparker a smart car parking for smart city scheme over a manual car parking system we construct a special online based car parking scheme, in this proposed system user makes and request to the central server for parking and book parking in advance by making a payment.

Extensive experiments are conducted to demonstrate the efficiency of the proposed scheme.

- Abundant works for searching a parking region have been proposed under Fastest neighbourhood node algorithm.

- Recently, some dynamic schemes have been proposed to support for parking and payment.

This paper proposes a secure FNN-based search scheme by revering a GPS location, and assure parking of car in advance. In this system one agent is proposed for keep attention on parking regions by obtaining time in time to 


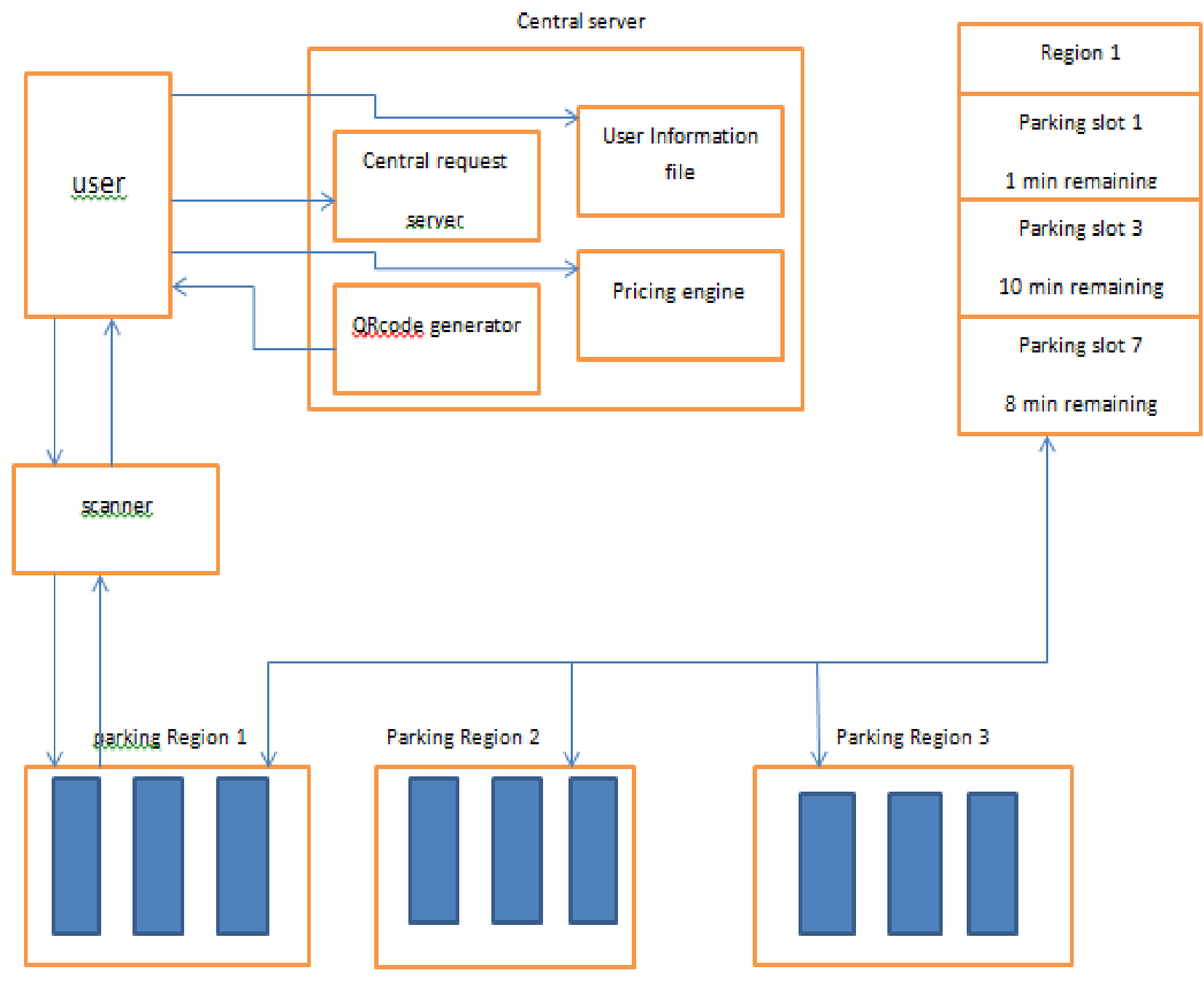

Fig 1: System Architecture

\section{SCOPE OF PROJECT}

In Internet oriented world there is need for movement from manual parking system to online management parking system, so this system provide effective parking system .[1]It is a platform which allows car driver for book a car parking in advance so there is less overhead for searching and parking very easily. Smart Parking lot design help optimise space and ensure that $15 \%$ more vehicles can be parked in the same space. Parking in India continues to remain very labourintensive the most popular method is pay on exit and the majority of parking systems use simple manual ticket problem at entry, with a flat rate for all-day parking and payment made in cash. Electronic handheld ticket issuing machines are also becoming popular. This management system help to build good business strategies. This is the one of the scope for smart city.

\section{MATHEMATICAL MODELS}

System $S$ is represented as $S=\{F, J, R, T, W, C\}$

A. Set $F=\{f 1, f 2, f 3 . f n\}$ Where, $F$ is shows as a set of locations and $\mathrm{f} 1, \mathrm{f} 2, \mathrm{f} 3 \mathrm{fn}$ are the number of location of corresponding entity.

B. User Ratings $U=\{u 1, u 2, u 3 \ldots u n\}$ Where, $U$ is represented as a set of user user location.
C.Location Mining Whiten same city by existing systemWhere,

$\mathrm{j}=\{\mathrm{j} 1, \mathrm{j} 2, \mathrm{j} 3 \ldots \mathrm{jn}\}$ whrere, $\mathrm{J}$ is represented as a set of confidence after visiting of right location from input and $j 1, j 2 j 3, \ldots, j n$ are the number of real ratings for the entity.

E.Dimensions neighbor $\mathrm{T}=\{\mathrm{t} 1, \mathrm{t} 2, \mathrm{t} 3, . . \mathrm{tn}\}$ Where, $\mathrm{T}$ is stands for as a set of nearest nebular and $\mathrm{t} 1, \mathrm{t} 2, \mathrm{t} 3$,..tn is number of neighbor.

F.Dimensions Weight: $\mathrm{W}=\mathrm{w} 1, \mathrm{w} 2$, w3, wn Where, $\mathrm{W}$ is representing as a set of Dimensions Weights and w1, w2, w3, wn are number of weights of a entity.

G. User Location Dimension Weight $X=\{x 1, x 2, x 3 \ldots x n\}$ Where, $X$ represents the set of Parking location Dimension Weight and $\mathrm{x} 1, \mathrm{x} 2, \mathrm{x} 3 \ldots \mathrm{xn}$ are the number of weight of overall user location.

F. Overall Trust Evaluation by confidence for find nearest neighbor.

$$
\begin{aligned}
& \mathrm{C}=\sum \mathrm{m} \\
& \mathrm{d}=1 \mathrm{td} * \mathrm{wd}
\end{aligned}
$$

Where, C - Overall Trust Score td-trust scope for dimension $\mathrm{d}=(1 \mathrm{~m})$ 
wd-weight for dimension $\mathrm{d}=(1 \mathrm{~m})$.

I.Overall Location distance Score $\mathrm{Os}=\mathrm{C}+\mathrm{X} / 2$

where, Os=Overall parking location $\mathrm{C}=$ Overall user location $\mathrm{X}=$ parking location Dimension Weight as compare to other parkings

\section{CONCLUSION}

In this proposed System iParker, a new smart parking system which is based on MILP model that incomes best solution for statically assigning parking resources to parkers providing flexible reservation choices.

The system suggested a pricing policies for static and reservations that maximize the profit from parking. Broad imitation results indicate that the proposed system significantly cuts the total real cost for all parkers by as much as $281 \%$, maximizes the total utilization by up to $211 \%$ and increases the total income for parking administration up to $161 \%$ as compared to the non-guided parking system. finally system found by simulations that it balances the utilization across all the parking resources and thus contribution in eliminating the overall traffic congestion caused by parking.

\section{REFERENCES}

[1] iParker-A New Smart Car-Parking System Basedon Dynamic Resource Allocation and PricingAmir O. Kotb, Yao-Chun Shen, Xu Zhu, Senior Member, IEEE, and Yi Huang, Senior Member, IEEElnewline

[2] Y. Ji, W. Guo, P. Blythe, D. Tang, and W. Wang, "Understanding drivers'perspective on parking guidance information," IET Intell. Transp. Syst.,vol. 8, no. 4, pp. 398-406, Jun. 2014.

[3] T. Rajabioun and P. Ioannou, "On-street and off-street parking availability prediction using multivariate spatiotemporal models," IEEE Trans. Intell.Transp. Syst., vol. 16, no. 5, pp. 2913-2924, Oct. 2015.

[4] M. Idris, Y. Leng, E. Tamil, N. Noor, and Z. Razak, "Park system: Areview of smart parking system and its technology," Inf. Technol. J., vol. 8,no. 2, pp. 101-113, Mar. 2009.

[5] G. Revathi and V. Dhulipala, "Smart parking systems and sensors: Asurvey," in Proc. ICCCA, Feb. 2012, pp. 1-5.

[6] N. Hanif, M. Badiozaman, and H. Daud, "Smart parking reservationsystem using Short Message Services (SMS)," in Proc. ICIAS, Jun. 2010,pp. 1-5 